\title{
A Study of Analyzing Oral and Written Feedback in Promoting Learning of Mathematics
}

\author{
Roohi Fatima \\ Department of Teacher Training and Non-formal Education (IASE), Faculty of Education, Jamia Millia Islamia, New Delhi \\ 110025, India.
}

\begin{abstract}
How to cite this paper: Roohi Fatima. (2021). A Study of Analyzing Oral and Written Feedback in Promoting Learning of Mathematics. The Educational Review, USA, 5(8), 295-300.

DOI: 10.26855/er.2021.08.006
\end{abstract}

Received: July 12, 2021

Accepted: August 8, 2021

Published: August 27, 2021

Corresponding author: Roohi Fatima, Department of Teacher Training and Non-formal Education (IASE), Faculty of Education, Jamia Millia Islamia, New Delhi 110025, India.

Email: rfatima@jmi.ac.in

\begin{abstract}
In this article, the author is attempting to find out whether feedback can be used to facilitate the teaching-learning process of mathematics or not? For this, she conducted an experimental study. The focus of this study is to find out whether the oral and written feedback makes any difference in the performance of students if it is provided after the tasks they had done in their class. This study was conducted to see the effect of enhanced feedback versus traditional feedback. Apart from this, she also tries to discuss the answers to the following questions: (1) What is the feedback? (2) What are the different methods of giving feedback? (3) Does feedback facilitates Meaningful Learning in mathematics? In this paper, the author is attempting to find out the answers to these questions since any attempt to answer these questions will necessarily involve a significant discussion on the effectiveness of feedback in the teaching-learning process of Mathematics.
\end{abstract}

\section{Keywords}

Feedback, Oral Feedback, Written Feedback, Learning of Mathematics

\section{Introduction}

In a classroom of a school, every room follows the same routine where teachers give instructions, provide work to do and then check it in their own way. There is only one type of checking which our teacher follows in the classroom. The same type of checking is done by the teacher after conducting a test in the classroom. This checking is conducted on the same paper and makes ticks for correct solutions and crosses for incorrect solutions and sometimes with grades attached which is not useful for students. In school, mostly teachers follow this type of checking routine in all subjects. The summative and formative assessment of the students in a school is also done in the same manner. As per NCF (2005), "Tests are designed (only) for assessing a student's knowledge of procedure and memory of formulas and facts, and given the criticality of examination performance in school life, concept learning is replaced by procedural memory". The assessment question is fact based and tests the memory of students and this routine is followed with ticks of right and wrong. More than that, if a teacher puts in some effort, they provide instruction to students about their mistakes and tell the procedure of correcting them. Here children do not know about the concept where he/she is lacking but start memorizing the procedure which they need to write in the examination. And the whole system depends on the examination procedure and the teaching of mathematics follows the route-memorization process in doing mathematics, which is temporarily learning. It does not include the nature of child learning. Children learn through formation of concepts not by memorizing the facts. So, there is a huge gap between the learning method of students and the feedback/instructions provided in the classroom by the teacher in mathematics discipline. As it is also observed by Bee and Kaur (2014) that "For mathematics, daily assignments are often marked piece after piece, with ticks and crosses. And such feedback is often of little use to students as it does not help them correct their errors or misconceptions”. William (2005) comments that "The key components of formative assessment are effective questioning, feedback, clear understanding of the crite- 
ria for success by learners as well as peer and self-assessment”. Thus, assessment followed with feedback gives detailed information to students about concepts but the assessment of having right and wrong is not beneficial for students.

\section{Concept of Feedback}

Feedback is about giving information in a way that encourages the recipient to accept it, reflect on it, learn from it and make changes for the better. In other words, it is a way of sharing information about the other actions, work or behavior from an individual or group to another group or individual and the motto behind the sharing of information is that another individual will improve the performance or try to maintain it. Information provided by a teacher after assessment is not only considered as feedback but also, the information given by teacher, parent, peer, book, self and their own experience.

Rama Prasad (1983) defined feedback as information about the gap between actual level and the desired level of performance, which in turn leads to corrective action to minimize the gap. Feedback is provided on a problem, task, performance of the child and the motive behind the feedback is to make the child aware about the desired goal or action that is demanded.

Teachers give feedback like 'keep it up', 'do some hard work' in the notebook and report cards of the students which give no effect on the performance of students. There are tasks stated in the notebook and feedback related to the particular task and particular problem make any effect on the performance of students. "Feedback has no effect in a vacuum" (Timperley \& Hattie, 2007). To address feedback, there must be a learning context in which children can work upon. Feedback without context is just a written statement which does not have aesthetic meaning. Teaching-learning processes include feedback as one of the major components. Without giving instruction about the concept and giving feedback to students, do not make any change in the learning. Feedback works effectively when it is provided during the teaching learning process and within the context of the task.

\section{Types of Feedback}

Hattie and Timperley (2007) state that some types of feedback are more powerful than others. Some studies show that students who receive information feedback about a task and how to do it more effectively show the highest effect than feedback which are related to praise, rewards, and punishment. A more detailed synthesis demonstrated that the most effective forms of feedback provide cues or reinforcement to learners; are in the form of video, audio or computer-assisted instructional feedback; and/or relate to goals. There is different type of feedback:

1) Evaluative and descriptive feedback

2) Oral, written and computer-mediated feedback

3) Individual or group feedback

4) Information or dialogue feedback

5) Immediate or delayed feedback

6) Positive or negative feedback

7) Informative or supportive feedback

8) Formative feedback

9) Reflection(self-feedback)

Thus, there are different types of the feedback and the above used terms for showing different types of feedback are self-explanatory. The effective feedback provides the learner with two types of information: verification and elaboration. Verification is defined as the simple judgment of whether an answer is correct, and elaboration is the informational aspect of the message, providing relevant cues to guide the learner toward a correct answer. Feedback elaboration has even more variations than verification. For instance, elaboration can (a) address the topic, (b) address the response, (c) discuss the particular error, (d) provide worked examples, or (e) give gentle guidance. "Researchers appear to be converging toward the view that effective feedback should include elements of both verification and elaboration" (Mason \& Bruning, 2001).

\section{Need of the study}

The researcher is a teacher educator, and also has a long experience as a school mathematics teacher. She observed many teachers and their way of giving feedback in mathematics, which is very disappointing. Teachers just make right and wrong ticks in the notebooks of the students and they use red pens for correction which highlight the mistakes of students. Sometimes, they make a big circle with a red pen in the notebooks and never put any effort in telling them about the portion which needs improvement. Teachers do not write any further process of solving the problem. Howev- 
er, such feedback is often of little use to students as it does not help them correct their errors. A child's mentality is totally affected with the red correct and wrong ticks. They compared their notebooks with their peer group and found themselves less knowledgeable in comparison with them. Here, the self-confidence of a child starts deteriorating piece by piece and he/she starts to lose confidence about the subject. Maybe this is one of the reasons that most children do not want to take mathematics in higher classes. In psychology, effective methods of teaching considered feedback as an important tool but positive not the negative one. Therefore, the researcher chooses this topic of study, i.e., to find the effective method of feedback in mathematics, and which has positive implications.

\section{Objectives of the Study}

The following are the objectives of the present study:

- To identify the need of feedback and its effect on promoting learning

- To observe the response of students towards oral and written feedback

- To measure performance of students after use of both oral and written feedback

- To compare the effectiveness of oral and written feedback

\section{Methodology}

For the present study, the researcher used an experimental method (quantitative method of data collection) for knowing the effect of feedback on the performance of students and also, semi-structured interview (qualitative method of data collection) for knowing the importance of feedback for both teacher and students. It includes both objective research and deeper insight of the problem in the problem area. In this research, the researcher makes two groups from the selected sample and gives different treatment to both groups. Oral feedback is given as treatment to group 1 and written feedback is provided as treatment to group 2. Here the same sample is used as a control group. Researchers first conduct a pre-test (task 1), then giving treatment to both the groups and then conduct post-test (task 2) for making inferences about the effect of the research problem. The present study relied on a multidimensional assessment procedure that included data collection from multiple sources and through multiple tools.

The present study was conducted in three phases:

1. Planning phase

2. Implementation phase

3. Analysis phase

Each of the phases is discussed below in detail.

\subsection{Planning Phase}

1) Population

The population in the present study comprised all the students of class VIII who studied in Government schools of Delhi. And all the TGT Mathematics of the government school, who taught Class VIII.

2) Sample of the Study

Researchers select one section of class VIII of one Government school (around 40 students) as a sample for the study. From them, 16 students were selected randomly, for an interview to know about feedback more deeply and interviewed 3 teachers who teach different sections of class VIII in the same school to know about their perception about feedback.

3) Tools of the Data

For the present study the researcher used various tools for data collection as relying upon a single tool does not help the researcher in fulfilling the objective of the study. Following tools were used by researcher for gathering the data:

The researcher constructed pre-test and post-test on content of algebra to use them as tasks performance of students. Pre-test was administered before the treatment to know the level of the students' understanding of algebra and errors committed by students of class VIII. Post-test was administered after the treatment was given by researchers to know the effectiveness of the treatment. Pre-test and post-test were given to five experts in the field of research and mathematics education for content validation.

In the present study semi-structured interview schedules were used to know the perception of students and teachers about the feedback given on the work done by students in their notebooks in solving mathematical problems.

For the purpose of collecting data, researchers developed two tasks containing 10 questions each related with the syllabus of class VIII NCERT book. The questions were based on the chapter 9 of Class VIII textbook, i.e., Algebraic Expressions and Identities. 


\subsection{Implementation Phase}

In the implementation phase following procedure is followed:

1) Administration of Pre-Test: The present study is primarily depending on the pre-test and post-test conducted by the researcher; the researcher introduces herself in the classroom and continue with the pretest on the content of chapter 9, i.e., algebraic expressions and identities, since they just finished this chapter in their class.

2) Intervention (Giving feedback on the pre-test based on algebraic expressions and identities): On the next three days, researchers give treatment to the students of the sample. Students were divided into two groups of 20-20 students as two samples. One group is provided treatment of oral feedback and other with the treatment of written feedback. The students were asked to go through the problems again after getting feedback and try to solve related problems given in the textbook.

3) Post Test to check the effectiveness of the intervention.

4) Interview schedule for Teachers: In the present study to know the perception of teachers about the feedback given on the work done by students in their notebooks in solving mathematical problems, a semi-structured interview schedule was used.

5) Interview schedule for Students: In the present study to know the perception of students about the feedback given on the work done by them in their notebooks in solving mathematical problems, a semi-structured interview schedule was used.

\subsection{Analysis of the Data}

The present study is both qualitative and quantitative in nature and the collected data is tasks responses and interviews of the teachers and students. So, for analyzing this data, researchers divide the content on the basis of objectives. Researcher divides the content between the objectives of the study;

- Objective 1 \& 2: These two objectives analyze the interview responses of teachers and students. It gives detailed information about the feedback that teachers use in the classroom and the benefits they feel of the given treatments as well as what are the responses of students towards oral and written feedback.

- Objective 3: This objective analyzes the data of experimental research. The collected tasks and the correct response students got were analyzed in this particular objective. Researchers use statistics to see the significant difference between both the tasks to measure the effect of oral and written feedback on the performance of students.

- Objective 4: This objective analyzes the effect of oral and written feedback in the classroom. It also analyzes the treatment that is provided by the researcher in written or oral form. And also try to find out what type of feedback researchers provided to bring change in the performance of students?

Each of the objectives is analyzed in detail with the provided data. This analysis was followed by interpretation of data by the researcher.

\section{Findings of the Study}

The objective wise findings of the present study were as follows:

\section{Objective 1 \& 2:}

1) To identify the need for feedback and its effect on promoting learning.

2) To observe the response of students towards oral and written feedback

The findings of these two objectives are;

- Research found that students want feedback (oral/written) in their classroom after any type of tasks conducted by the teacher in the mathematics classroom.

- One major finding of the study is that students demand feedback at individual level—it can be either in their notebooks (written feedback) or face-to-face with the teacher (oral feedback).

- It was found that students do not want the explanation of problems on the board second time but they want it in their individual notebooks.

- It was also found that both written and oral feedback is helpful according to demand of the tasks.

- School teachers do know about the feedback term but they do not know the real meaning and use of feedback for the students.

Objective 3: To measure performance of student/s after use of both oral and written feedback in the classroom. 
- The experimental research conducted reveals that feedback gives impact on the performance of the students.

- This research found that both types of feedback make an effect on the performance of students.

- Another finding of the research states that feedback is helpful in promoting learning of students in the classroom.

- It was found that immediate feedback has more effect on the students than delayed feedback.

Objective 4: To compare the effectiveness of oral and written feedback.

- It was found that oral feedback is more suitable for the students then written feedback

- Written feedback makes students more attentive in the classroom.

- Study found that written feedback helps in starting out a conversation (talk) that facilitates learning.

- Another finding of the study was that feedback helps in start talk between peers which is based on some content of learning.

- Feedback containing the names of students gives positive vibes to students and strengthens their energy to respond.

\section{Conclusion}

Through this study, it can be concluded that schools do not use any type of feedback process in the classroom. They still use the traditional method of giving marks in numbers even after the government started the CCE scheme in schools. It includes formative evaluation where they need to give feedback to students but the situation has not changed. Now, researchers found that schools should provide written feedback to students which can decide according to the need of the students. As written feedback is effective for the students who know to read and oral feedback is effective for others. Students demand feedback and want feedback-based checking in their classroom after the tasks. Feedback has many positive effects that can bring change in the education system like it makes students more attentive than usual days because they always have something new for themselves. Feedback should be included for all the subjects in the schools. It makes an impact on the performance of students very deeply.

\section{Educational Implications}

Following are the educational implications of this study.

- There is a need to include the way of giving feedback (process of feedback) in the pre-service teacher training programme. It will help teachers in understanding the importance and use of feedback.

- Feedback should be included in the curriculum as a compulsory activity of the classroom after every task of the subject.

- There should be autonomy to teachers in deciding what type of feedback is good for the students and what feedback is needed in a particular activity. A teacher is a best knower of his/her students.

- Teachers can develop mathematics journals for students in which they can give feedback regularly and talk to students about their problems also.

- There is a need to break the old tradition of giving feedback in the form of marks and right and cross tick. Teachers should be aware about the benefits of feedback in the classroom, so they can use it properly.

- There is a need to conduct more and more studies in mathematics in order to resolve the problem of school performance of students.

\section{Suggestions for Further Research}

These are suggestion by researcher for the further research:

- Research can be conducted to know about the different effects of feedback on the performance of students.

- Research can be done to know about the effect of the feedback in the development of life of students.

- Mathematics journal is one of the new concepts, which start the use of language in the classroom, so research can be conducted in knowing the result after use of a mathematics journal in the classroom.

\section{Acknowledgements}

I would like to acknowledge Ms. Ayushi Tomar (2016-18), a student of M.A. (Education), Department of Teacher Training and Non-formal Education, Jamia Millia Islamia in helping me in gathering the data for the study. 


\section{References}

Banerjee. (2014). Improving student’s learning with correct feedback. International Journal of Education and Psychological Research, Volume 3, Issue 4.

Bee and Kaur. (2014). Using enhanced feedback to improve the learning of mathematics. The Mathematics Educator, Vol. 15, No. 2, 101-119.

cei.ust.hk/learner-centered-courses-design/leaning-assessment/feedback-enhance-learning.

Fyfe and Johnson. (2017). Mathematics practice without feedback. Springer, 45: 177-194.

http//www.snapsurveys.com/blog/5-reasons-feedback-importance.

xwww.1000ventures.com/buisness-guide/crosscuttings/feedback-3types-me.html. 